\title{
Can we Increase Identifications in 48-Person Lineups by Asking for Ratings of All Lineup Members?
}

\author{
Avraham Levi* \\ Public Defenders, Israel \\ Submission: February 08, 2018; Published: March 12, 2018 \\ *Corresponding author: Avraham Levi, Public Defenders, 33 Palyam Rd. Jerusalem 97890, Israel, Tel: 972-2-5815284; \\ Email: avmlevi@netvision.net.il
}

Abstract

A fair lineup is one in which each of the foils and the innocent or guilty suspect have an equal chance of being chosen by people who have never seen the suspect ["mock witnesses", who have been given a description of the target. The lineup is the safest eyewitness identification procedure, because the foils provide some protection to an innocent suspect. However, it is far from perfect. There is ample evidence that witnesses often choose someone who is not the culprit. When they choose, and that person is not the suspect but a known innocent, the police know that they have erred. However, in a fair simultaneous lineup by chance these witnesses who choose "identify" a suspect who is innocent $1 / \mathrm{N}$ times, where $\mathrm{N}$ is the lineup size. With the common American lineup size of six, this will happen $1 / 6=0.167$, or almost $17 \%$ of the time.

\section{Introduction}

There is a second error that witnesses often make which goes undetected by the police: witnesses fail to identify guilty suspects [1-5]. While a number of innovative lineup procedures have been developed to reduce mistaken identifications, there have been few procedures available to increase correct ones that do not simultaneously increase mistaken ones [6-9]. The danger of mistaken identifications has been considered so great that in the wake of research showing that we can reduce them if we warn witnesses that the culprit may not be in the lineup, the warning has been included in one of four recommendations of a White Paper of the American Psychological Association to improve lineup identification evidence [10].

Yet experimental witnesses choose someone $57 \%$ of the time when the «culprit» is absent when shown a simultaneous lineup, even with the warning. In a fair lineup, the innocent suspect will be chosen in the traditional six-person American lineup 57/6= 9.5\% of the time [11]. This seems quite a large danger for an innocent suspect. Lindsay and Wells introduced sequential lineups [8]. Their data, and a meta-analysis, indicate that its chief advantage is in reduced mistaken identifications [12]. Only $36 \%$ mistaken choices in culprit-absent lineups are made. Thus, in the traditional six-person American lineup the innocent suspect will be chosen $36 / 6=6 \%$ of the time. This remains too large a large danger for an innocent suspect [5].

Levi et al. [13] proposed exploring large lineups. They theorized that enlarging lineups could reduce false recognitions, if the rate by which witnesses chose someone in target-absent lineups increased less than the increased lineup size. Thus, if a 40-person lineup had the same rate of mistaken choices as the six-person lineup, the number of false identifications would be $57 / 40=1.04 \%$. This is clearly a tremendous improvement. Early research seems to have discouraged exploring this approach [14-16]. However, this research showed only one photo at a time. Conducted a series of experiments to test the effects of showing more than one photo at a time $[17,18]$. There remained a choice between "simultaneous" and «sequential» lineups. The little research on lineup size to date has been with the sequential lineup. It could also be adapted to grouping photos. Witnesses could view each page one after the other, announcing whether they had identified the culprit before moving on to the next page [17]. This would maintain the inability of witnesses to pick the person most similar to the culprit, since they would not know whether he or she might appear on the next page.

However, the "simultaneous" format was chosen. The sequential lineup's advantage is in decreasing incorrect recognition [11]. However, enlarging lineups has the potential of decreasing mistaken identifications much more. If the number of mistaken choices in target-absent lineups remains constant with increase in size for simultaneous lineups, then 24-person lineups will have no more false recognitions than six-person sequential ones. If these mistaken choices continue to remain constant as lineup size continues to double, the sequential advantage could become marginal. It seemed best to attempt to maintain the larger number of culprit identifications of simultaneous lineups, relying on increased lineup size to reduce mistaken identifications. 
Using the term «simultaneous» with grouped photos can be misleading. All the photos were not shown simultaneously, but rather in groups over a number of pages. The term was nonetheless maintained, to emphasize the distinction between the inability of witnesses to pick the person most similar to the culprit in the sequential format and their ability to do so in the "simultaneous" lineup adopted: witnesses were informed that they could leaf back and forth between the pages before making their decision. This seems to be the critical element of the simultaneous lineup that enables more identification, yet causes more mistaken ones [19].

The purpose of this research program was to discover approximately the largest lineup that was feasible using the grouping strategy. In order to do so, it was necessary to reach a lineup size that was too large. It seemed reasonable to double the lineup size each time, as a method to quickly reach a lineup too big. Clearly the critical question was how many photos witnesses could view before the sheer number would begin to confuse them and reduce identifications. In all the cited studies one photo or video-clip had been shown at a time. The alternative was to group photos, showing each group at a time. Witnesses may be better at identifying culprits this way. The grouped format enables witnesses to reject all but the member most similar to the culprit relatively quickly. They need to make the more difficult decision of rejecting or accepting that final lineup member only once for each set of photos. The difference in effort may not be noticeable in six-person lineups, but as lineups grow in size (to 40 , for example) the strain on witnesses might become substantial, decreasing the cognitive resources required for successful identification.

On the other hand, showing witnesses 40 or more photos simultaneously may create a different task difficulty, the task of comparing simultaneously so many photos. A balance of fewer photos per page over a number of pages may produce the best identification results. The purpose of the research program was to discover approximately the largest lineup that was feasible using the grouping strategy. In order to do so, it was necessary to reach a lineup size that was too large. It seemed reasonable to double the lineup size each time, as a method to quickly reach a lineup too big. Clearly the critical question was how many photos it was possible to show witnesses before the sheer number of photos would begin to overwhelm them. Surprisingly, he did not manage to reach that number with a lineup of 120 members. There is however one important caveat. The number of photos on each page makes a tremendous difference: no more than twelve photos can be shown. Thus, the 120-photo lineup consists of ten pages.

Another relevant finding was that lineup size did not affect the number of mistaken choices. Thus, if we take the average of $57 \%$ mistaken choices in six-person lineups the rate of expected mistaken identifications in a 120 -person lineup is $57 / 120=$ $0.475 \%$ [11]. It seems that the large lineup has a tremendous advantage over even the sequential lineup with a $6 \%$ chance. Levi had established clearly that large lineups are far superior to any other because of the far smaller rate of mistaken identifications. The research program now turned to finding ways of increasing correct identifications. Levi tried to use the eye tracker, a device that photographs the movement and location of the eyes' gaze at some stimulus [20]. According to a popular conceptualization espoused by (relative judgment), witnesses with poorer memory of the culprit compare between lineup members, and often simply choose the person who seems to look most like the culprit-often the innocent suspect. Translating this into gaze behavior, in comparing between lineup members the attention of these witnesses will be on some of them in addition to the time spent concentrating on the culprit. Perhaps more time will be spent gazing on the culprit, but not a tremendous more time. On the other hand, witnesses with relatively good memory of the culprit are expected to spend far less time gazing at the other lineup members.

Indeed, witnesses using this absolute strategy tend to spend less time in making their identification [21-23]. This less time should be concentrated far more on the culprit. Translating this into gaze behavior, while they might be expected to at least glance at the other lineup members, a reasonable expectation would be that they spend much more time looking at the culprit than at any other lineup member. The more important different behavior occurs when the culprit is not in the lineup, when the suspect is innocent. Witnesses with good memory should be able, after glancing at the lineup members, to decide that the culprit is absent. Other witnesses will compare between lineup members and choose the person most resembling their memory of the culprit, who all too often will be the innocent suspect (unless of course all the lineup members differ tremendously from the culprit, which should not happen in a fair lineup).

These conflicting predictions led to a promising outcome: witnesses who dwell a relatively long time on the suspect have identified the culprit. On the other hand, if the suspect who is chosen does not stand out as having been looked at so much longer than any other lineup member, he/she was most likely chosen using relative judgment, and therefore is likely innocent.

This analysis differs from that of Mansour et al. [24]. That paper states that if a witness looks at all the faces in a lineup, this is indicative of relative judgment. This position contrasts with

this paper, which expects witnesses to at least glance at all the faces. Relative judgment is indicated only if the witness fails to focus much longer on the person chosen.

The relatively small 48-person large lineup was used primarily to make it easier to experimentally check the results of the experiment. It makes little difference to police forces whether they would use a 48-person compared to a 120 -person lineup. They have at their disposal thousands of appropriate foils for almost any suspect. On the other hand, researchers do not. 
The smaller the lineup, the easier it is to acquire the photos. This experiment began using a somewhat more realistic eyewitness event in the past. Up to now, the experimenter visited offices with a young assistant. If the potential participant expressed willingness to be in the experiment, the young assistant found a mutually acceptable time and asked for their name and phone number. When the experimenter returned to conduct the experiment, the participant was informed that they were to view a lineup, the «culprit» being the young assistant.

Thus, the recruitment stage was also the eyewitness event, and a very difficult one at that. Participants had no idea that such an event was taking place. Moreover, they hardly paid attention to the «assistant», which seemed to merely performing a clerical function for the experimenter. Indeed, quite low rates of identification were achieved in all experimental conditions. The new eyewitness event was quite different. At the time of recruitment, participants were shown a two-minute video, a family scene featuring four adults, a baby, and numerous other items. The one advantage for participants of this event over the previous one is that they knew that they were supposed to remember something. However, the event was short and they had no idea that they were supposed to remember one of the adults.

The results strongly negated the relative judgment conceptualization: witnesses most often focused on some foil when they did not identify the target in target-present lineups, or could not do so in target absent ones. Adding up the two cases, 52 of 62 cases failed to act according to the relative judgment conceptualization. By the binomial, the probability that so many cases would be contrary to the theory is $\mathrm{p}<0.0001$ (two-tailed). This experiment did not merely fail to reject the null hypothesis. If found results exactly the opposite of the research hypothesis, very significant statistically. Our «culprit» was identified $30.5 \%$ of the time. We now turn to another attempt to increase identifications in 48-person lineups. The danger of mistaken identifications has been considered so great that in the wake of research showing that we can reduce them if we warn witnesses that the culprit may not be in the lineu, the warning has been included in one of four recommendations of a White Paper of the American Psychological Association to improve lineup identification evidence $[4,10]$. With a typical rate of $50 \%$ mistaken choices in the traditional six-person targetabsent simultaneous lineup, if the lineup is fair the expected rate of mistaken identifications is $50 / 6=8.3 \%$. With a lineup of 48 , the same percentage of mistaken choices leads to $50 / 48=$ $1 \%$ mistaken identifications. What might happen, then, if the warning was omitted before a 48-person lineup? We might expect an increase in mistaken choices, perhaps to about $75 \%$ in target-absent lineups, and therefore mistaken identifications would be $75 / 48=1.56 \%$. We would thus be paying the price of about half a percent more mistaken identifications by omitting the warning. The empirical question was what the gain in target identifications will be if the warning is omitted.
Therefore, an experiment was conducted which included the 48-person lineups with or without the warning and with the target present or absent $[25,26]$. The results were as disappointing as they were clear-cut. While the expected increase in mistaken choices occurred when the warning was omitted in target- absent lineup, there was no difference whatsoever in target-present ones. This contrasts with the evidence from six-person lineups [27]. We now turn to yet another attempt to increase identifications in the 48-person lineup. Brewer [28] has presented data of a new method that has worked for him with small lineups. The rationale is the same as was suggested for the eye tracker study: Some witnesses are hesitant to identify someone if they are not sure. Brewer, instead of asking witnesses to identify someone, asked them to rate all the lineup members regarding the likelihood that each one was the target. The purpose of this experiment was to test whether this alternate method would improve the rate of identification in the 48-person lineup.

\section{Method}

\section{Participants}

The 100 participants in this experiment were graduate students at the Givat Ram and Mt. Scopus campuses of the Hebrew University in Jerusalem, Israel who agreed to participate in a short and interesting experiment on memory which would involve viewing a two-minute video immediately, and later participating in a five- minute experiment in their office/lab. There were 29 male participants, and 71 female ones. The average age of the participants was 25.6.

\section{Design}

50 participants were given the new instruction to rate all lineup members, the other 50 were given the standard instruction to identify the target if he was present in the lineup. Only target-present lineups were used, as the rate of mistaken identifications is known for the 48-person lineup, and the issue at hand was whether more correct identifications could be achieved with the rating method.

\section{Recruitment and Eyewitness Event}

The author visited offices and labs at the university. He introduced himself, and asked the occupant whether they would participate in an interesting experiment in their lab at a later time that would last only about five minutes. If a person agreed, he immediately showed them one of four videos in their office lasting 2 minutes in which the target and other people were seen. He arranged a mutual acceptable time for the experiment, at least an hour later. The video and the lineup were shown on a laptop computer.

\section{The Lineup}

Photos for the lineups were chosen from Levi [7]. All lineup members were young adult males who had dark and short hair, 
dark eyes, no beard or moustache, and were of medium build. The target also fit this description. The twelve faces of each screen were organized in two lines of six. The target was placed in the lower line one before the end from the right.

\section{Lineup Procedure}

Witnesses in the traditional condition were told: «I am now going to conduct a lineup. The person you are to identify is the male in the video [who moved around or was the only man or was the man bare chested, depending on which video they had been shown]. He may or may not be in the lineup. The lineup consists of 4 screens with 12 photos in each one. Since all the photos are different, the person can only appear in one screen, if at all. You may view the screens as many times as you want before coming to your decision.

\section{Witnesses in the Rating Condition were told}

I am going to conduct a lineup. The person I am interested in the male in the video [who moved around or was the only man or was the man bear chested (depending on which video they had been shown)]. The lineup consists of 4 screens with 12 photos in each one. I will show you the screens, one after the other. For each screen rate each person, from one to twelve, regarding the likelihood that he is the person I am interested in (use a percentage).

\section{Results and Discussion}

As with Brewer, the lineup member who was rated highest was considered the one who was identified. The number of correct identifications for the traditional lineup was 10, for the ratings lineup 2 . By the test for the difference between two proportions, $\mathrm{z}=2.183, \mathrm{p}<0.0292$ (two-tailed) [29]. Thus, the traditional lineup was superior to the ratings lineup. We note the critical difference between Brewer's rating lineup and the one employed in this study. The present lineup was far larger, consisting of 48 members on four screens. From the observation of the author/experimenter, two factors seem to be involved in reducing the number of identifications. One the one hand, the large number of ratings required may have made concentration difficult. On the other hand, some witnesses gave a relatively high rating to a lineup member on an early screen, and gave a slightly lower, or equal, rating to the culprit who appeared on a later screen. They simply may not have remembered their precise earlier rating. Since there is little research on 48-person lineups, it would be difficult to determine the real cause for the discrepancy between the results between the two lineup sizes. In all events the research that has been conducted on 48-person lineups confirms that all police forces, including European ones, would be best advised to switch to 48-person ones. It has such a tremendous advantage over all other lineups in use today in preventing mistaken identifications.

\section{References}

1. Doob AN, Kirshenbaum HM (1973) Bias in police lineups-partial remembering. Journal of Police Science and Administration 1: 287-293.
2. Conners E, Lundregan T, Miller N, Mc Ewen T (1996) Convicted by juries, exonerated by science: Case studies in the use of DNA evidence to establish innocence after trial. Department of Justice, Washington, USA.

3. Valentine T, Pickering A, Darling S (2003) Characteristics of eyewitness identification that predict the outcome of real lineups. Applied Cognitive Psychology 17(8): 969-993.

4. Wells GL, Small M, Penrod S, Malpass RS, Fulero SM, et al. (1998) Eyewitness identification procedures: Recommendations for lineups and photospreads. Law and Human Behavior 22(6): 603-647.

5. Levi AM (1998) Are defendants guilty if they were chosen in a lineup? Law and Human Behavior 22(4): 389-407.

6. Levi AM (2006) An Analysis of Multiple Choices in MSL Lineups and a Comparison with Simultaneous and Sequential ones. Psychology Crime \& Law 12(3): 273-285.

7. Levi AM (2012) Much Better than the Sequential lineup: A 120-person lineup. Psychology Crime \& Law 18(7): 631-640.

8. Lindsay RCL, Wells G (1985) Improving eyewitness identifications from lineups: Simultaneous versus sequential lineup presentation. Journal of Applied Psychology 70(3): 556-564.

9. Pryke S, Lindsay RCL, Dysart JE, Dupuis P (2004) Multiple independent identification decisions: A method of calibrating eyewitness identifications. Journal of Applied Psychology 89(1): 73-84.

10. Malpass RS, Devine PG (1981) Eyewitness identification: Lineup instructions and the absence of the offender. J App Psychol 66(4): 482489.

11. Steblay NK, Dysart JE, Wells GL (2011) Seventy-two tests of the sequential lineup superiority effect: A Meta-Analysis and Policy Discussion. Psychology Public Policy and Law 17(1): 99-139.

12. Dupuis P R, Lindsay RCL (2007) Radical alternatives to traditional lineups. In R Lindsay, R Ross, D Read, M Toglia (Eds.) Handbook of eyewitness psychology: Memory for people, Mahwah, Lawrence Erlbaum and Associates, New Jersey, USA, 2: 179-200.

13. Levi AM, Lindsay RCL (2001) Lineup and photo spread procedures: Issues concerning policy recommendations. Psychology Public Policy and Law 7(4): 776-790.

14. Levi AM (2015) When the relative judgment theory proved to be false. Psychology and Law 5(4): 141-149.

15. Davies G, Shepherd J, Ellis H (1979) Effects of interpolated mugshot exposure on accuracy of eyewitness identification. Journal of Applied Psychology 64(2): 232-237.

16. Laughery KR, Alexander JF, Lane AB (1971) Recognition of human faces: effects of target exposure time, target position, pose position, and type of photograph. J App Psychol 55(5): 477-483.

17. Levi AM (2006) A Comparison Between Large Simultaneous and MSL Lineups, with Photos Viewed in Sets of Six. In K Nixon (Eds.), Forensic recall and eyewitness testimony. IA-IP Publishing, London, England, pp. 91-101.

18. Levi AM (2007) Evidence for Moving to an 84-Person Photo Lineup. Journal of Experimental Criminology 3(4): 377-391.

19. Wells GL (1984) The psychology of lineup identifications. Journal of Applied Social Psychology 14(2): 89-103.

20. Holmquist $K$, Nystrom M, Andersson R, Dewhurst R, Jarodzka H, et al. (2011) Eye Tracking. Oxford: Oxford Press, USA.

21. Scheck B, Neufeld P, Dwyer J (2001) Actual innocence: When justice goes wrong and how to make it right. New York, USA.

22. Sporer SL (1993) Eyewitness Identification Accuracy, Confidence, and Decision Times in Simultaneous and Sequential Lineups. Journal of Applied Psychology 78(1): 22-33. 
23. Steblay NM (1997) Social influence in eyewitness recall: A meta-analytic review of lineup instruction effects. Law and Human Behavior 21(3): 283-297.

24. Mansour JK, Lindsay RCL, Brewer N, Munhall KG (2009) Characterizing visual behavior on a lineup task. Applied Cognitive Psychology 23(7): 1012-1026.

25. Levi AM Partial memory: another reason for using large lineups?

26. Valentine T, Davis JP, Memon A, Roberts A (2012) Live Showups and Their Influence on a Subsequent Video Line-up. Applied Cognitive Psychology 26(1): 1-23.
27. Clark SE (2005) A Re-examination of the Effects of Biased Lineup instructions in eyewitness identification. Law and Human Behavior 29(4): 395-424.

28. Brewer N (2017) The problem of lineups. Sarmac XII, Sydney, Australia.

29. Walpole RE (1968) Introduction to statistics. Macmillan Company, New York, USA

\section{Your next submission with Juniper Publishers} will reach you the below assets

- Quality Editorial service

- Swift Peer Review

- Reprints availability

- E-prints Service

- Manuscript Podcast for convenient understanding

- Global attainment for your research

- Manuscript accessibility in different formats

( Pdf, E-pub, Full Text, Audio)

- Unceasing customer service

Track the below URL for one-step submission https://juniperpublishers.com/online-submission.php 